\title{
Turtles on the trash track: loggerhead turtles exposed to floating plastic in the Mediterranean Sea
}

\author{
A. Arcangeli ${ }^{1, *}$, F. Maffucci ${ }^{2}$, F. Atzori ${ }^{3,4}$, M. Azzolin ${ }^{5}$, I. Campana ${ }^{6}$, L. Carosso ${ }^{6}$,
} R. Crosti $^{1}$, F. Frau ${ }^{3}$, L. David ${ }^{7}$, N. Di-Méglio ${ }^{7}$, M. Roul ${ }^{7}$, M. Gregorietti ${ }^{8}$, V. Mazzucato ${ }^{6}$, G. Pellegrino ${ }^{6}$, A. Giacoletti ${ }^{9}$, M. Paraboschi ${ }^{6}$, A. Zampollo ${ }^{5}$, G. A. de Lucia ${ }^{10}$, S. Hochscheid ${ }^{11}$

${ }^{1}$ ISPRA, Department for Biodiversity Conservation and Monitoring, Via Brancati 48, 00143 Rome, Italy ${ }^{2}$ RIMAR Department, Stazione Zoologica Anton Dohrn, Villa Comunale, 80121 Naples, Italy

${ }^{3}$ Capo Carbonara MPA- Municipality of Villasimius, 09049 Villasimius (SU), Italy

${ }^{4}$ Department of Ecological and Biological Sciences, Ichthyogenic Experimental Marine Center (CISMAR), Tuscia University, Borgo Le Saline, 01016 Tarquinia, VT, Italy

${ }^{5}$ Gaia Research Institute, Corso Moncalieri 68B, 10133 Torino, Italy

${ }^{6}$ Accademia del Leviatano, Via dell'Ospedaletto 53/55, 00054 Maccarese, RM, Italy

${ }^{7}$ EcoOcéan Institut, 34090 Montpellier, France

${ }^{8}$ BioacousticsLab, CNR-IAS, Institute of Anthropic Impact and Sustainability in Marine Environment - National Research Council, Via del Mare 3, 91021 Torretta Granitola (TP), Italy

${ }^{9}$ Department of Earth and Marine Science (DiSTeM), Laboratory of Ecology, University of Palermo, Viale delle Scienze Ed. 16, 90128 Palermo, Italy

${ }^{10}$ CNR-IAMC, Institute for Coastal Marine Environment - National Research Council, Torregrande (OR), Italy

${ }^{11}$ Marine Turtle Research Center, Stazione Zoologica Anton Dohrn, Via Nuova Macello 16, 80055 Portici, Italy

\begin{abstract}
Loggerhead turtles Caretta caretta spend most of their life in large marine areas occupying a variety of habitats where they are exposed to different types of threats. Among these, marine litter poses a risk of entanglement or ingestion. Areas of risk exposure can be identified where the species overlap with litter accumulations, but gathering data on this highly mobile species and marine litter, especially in high sea areas, is challenging. Here we analysed 5 years of sea turtle and marine litter data collected by a network of research bodies along fixed trans-border transects in the Mediterranean Sea. Ferries were used as observation platforms to gather systematic data on a seasonal basis using standard protocols. Loggerhead turtle sightings over time and space were compared in terms of sightings per unit effort, and risk-exposure areas were assessed based on seasonal overlap of species hot spots and high-density plastic areas revealed by kernel analysis. In almost $180000 \mathrm{~km}$ surveyed, 1258 sea turtles were recorded, concentrated mostly in the central Adriatic Sea and Sardinia-Sicilian channels during all seasons, and in the central Tyrrhenian Sea during spring. Plastic comprised the highest fraction of litter items detected. Several areas of higher risk exposure, both permanent and seasonal, were identified, mainly in the Adriatic Sea and during the spring-summer seasons. Records of both species and floating litter were highly variable, underlying the need for continuous long-term monitoring to develop sound conservation and management measures, especially in the identified areas of risk exposure.
\end{abstract}

KEY WORDS: Loggerhead turtle $\cdot$ Caretta caretta $\cdot$ Marine litter $\cdot$ Mediterranean Sea $\cdot$ Monitoring Risk assessment

\section{INTRODUCTION}

Effective management of an endangered species requires knowledge of its spatio-temporal distribu-

${ }^{*}$ Corresponding author:

antonella.arcangeli@isprambiente.it tion throughout its life history, particularly for those species that have a complex life cycle and use a variety of ontogenetic habitats. Simultaneously, it is essential to know when and where a specific anthropogenic

(C) The authors 2019. Open Access under Creative Commons by Attribution Licence. Use, distribution and reproduction are unrestricted. Authors and original publication must be credited. 
stressor co-occurs with the species' presence, in order to mitigate the threat in the right place and time. Thus, identifying priority conservation areas where critical habitats overlap with anthropogenic threats is one of the driving research objectives of conservation scientists. However, place-based management is especially challenging in the highly dynamic and vast marine environment, where the distribution of large marine vertebrates is closely linked to ocean processes and the distribution of their prey (Scales et al. 2014, Briscoe et al. 2016).

The effectiveness of at-sea management approaches faces many challenges, one of which is to know and predict the occurrence of the species of interest. Many of the threatened marine megafauna, such as cetaceans and sea turtles, are migratory species that use specific sea regions only at certain times of the year, or at certain stages of their lives. Satellite tracking has become increasingly used to identify important marine areas and migratory corridors (Godley et al. 2008, Snape et al. 2016, Hays \& Hawkes 2018), yet this method allows only tracking of individual animals, and even if a satellite tracking study involves a large sample size ( $\mathrm{n}>50$ ), it may still not represent the whole population because of sampling biases and technological limitations (Godley et al. 2008). On the other hand, monitoring programmes with repeated surveys at sea can deliver absolute abundance or proxies of abundances for animals occurring in a survey area (Vorisek et al. 2008, Thomas et al. 2010). Ideally, a monitoring programme would need to cover a large enough area to ensure that a significant portion of a population is observed, and would have to be repeated at meaningful intervals over long time periods to reveal intra- and inter-annual variations in abundances and to detect population trends.

To date, systematic long-term surveys of at-sea distributions and abundances of sea turtles in the Mediterranean have not yet been carried out. The loggerhead turtle Caretta caretta (Linnaeus, 1758) is the most abundant sea turtle species in this region and is listed as Least Concern by the IUCN Red List of threatened species (Casale et al. 2015). Many international conventions and agreements protect the species in the Mediterranean Sea (e.g. Convention on Biological Diversity, Convention on the Conservation of Migratory Species of Wild Animals, Convention on International Trade in Endangered Species of Wild Fauna and Flora), among which the EU Habitats Directive 92/43/ CEE currently lists C. caretta as a priority species whose conservation requires the designation of special areas of conservation. Most of what is known about marine areas for loggerhead turtles in the
Mediterranean has been inferred from either satellite tracking studies, fishery by-catch data, mark-release and recapture data, and stranding records (for a recent overview, see Casale et al. 2018). In brief, while loggerhead turtles and especially their juveniles can be found in virtually all oceanic areas in the Mediterranean Sea, data derived from fishery by-catch rates indicate relatively high abundances in the westernmost part of the basin, the southern Sicily Channel, and the northern Ionian/southern Adriatic Sea (Casale et al. 2018). In the Tyrrhenian Sea, catch rates are lower, but nonetheless, recent studies have also highlighted the Tyrrhenian Sea as an important oceanic area for this species (Blasi \& Mattei 2017, Luschi et al. 2018). Unfortunately, no comparable by-catch rates are available for other areas in the eastern Mediterranean, although high turtle abundances could be expected there because of the proximity of its oceanic areas to known nesting beaches (Casale et al. 2018).

When considering actual at-sea counts of turtles, to date only 3 published studies have used aerial surveys to report abundances of loggerhead turtles in the Western Mediterranean: a $32000 \mathrm{~km}^{2}$ oceanic area in eastern Spain (Gómez de Segura et al. 2006), a $477 \mathrm{~km}^{2}$ neritic area around the Balearic Archipelago (Cardona et al. 2005), and a $90000 \mathrm{~km}^{2}$ mostly pelagic area in the Ligurian Sea (Lauriano et al. 2011). The latter study also demonstrates a seasonal difference in turtle abundance, with a drop during the winter months. The whole Adriatic Sea was also surveyed by aerial surveys in 2013 as part of the NETCET Project (www.netcet.eu), which reported a minimum number of around 31000 turtles, mostly occurring in the northern sections, with fewer sightings in the central-southern Adriatic (Štrbenac 2015). However, there were too few repeated assessments in these studies to monitor for inter- and intra-annual variations or examine long-term trends of loggerhead abundance. This is most likely due to the high costs involved in carrying out large-scale aerial surveys, and hence the difficulties in securing continued funding for such monitoring programmes.

The most recent IUCN Red List assessment was mainly based on a few long-term data series on nesting females. While this assessment result clearly reflects the success of long-term conservation projects established in this region, it also highlighted important knowledge gaps, namely the need for continuous data from foraging grounds and for mortality rates caused by anthropogenic activities (see also Casale et al. 2018). The main threats to the Mediterranean subpopulation, as for many populations elsewhere in the world, are fishery bycatch and nesting 
habitat degradation due to coastal development (Casale \& Margaritoulis 2010). However, pollution, one of the ' 5 hazards to sea turtles' (Wallace et al. 2011), has also been identified as a serious threat for many regions in the Mediterranean (Casale \& Margaritoulis 2010). Initially, studies investigating the impact of pollution on marine biota were concerned with the presence and concentrations of xenobiotics in marine food webs, but more recently, there has been a shift in attention towards the impact of marine litter (e.g. Nelms et al. 2015). Indeed, plastic marine litter has developed into a high-profile international environmental issue over the last 2 decades (Gold et al. 2013, Jambeck et al. 2015). Current research aims to understand the degree to which animals are exposed to marine litter and the potential impacts of plastic ingestion and entanglement on marine wildlife (Nelms et al. 2015, Avery-Gomm et al. 2018).

The harm caused by marine litter to wildlife is determined by the combination of the likelihood of colliding with, ingesting, or becoming entangled in plastic items, and the consequences of these interactions (Darmon et al. 2016, Guerrini et al. 2019). Gastro-intestinal obstruction, internal injuries, a false sense of satiation with decreased absorption of nutrients, and disruption of the endocrine system due to the consumption of leached toxic substances are amongst the most commonly reported consequences of plastic ingestion. In addition, entanglement of turtles in marine debris can cause physical damage and obstruction of the head and flippers, which may cause alterations in movements and buoyancy, thus preventing the turtle from swimming, diving, breathing, and feeding. These effects influence the health of individuals, and may lead to changes in demographic characteristics, such as reproductive fitness and mortality. Yet to understand the impact of marine litter at the population level requires understanding of the degree to which turtles are exposed to marine litter (Avery-Gomm et al. 2018).

Sea turtles have been used as bio-indicators for marine pollution worldwide (Galgani et al. 2013, Nelms et al. 2015), and the impacts of marine litter on marine fauna have been identified as one of the 11 descriptors within the Marine Strategy Framework Directive (MSFD; Criteria D10C3, Commission Decision EU 2017/848). Recent studies in this sea region have shown that sheet-like plastic fragments (e.g. pieces of shopping bags) are the most commonly found type of debris ingested by loggerhead turtles (Camedda et al. 2014, Casale et al. 2016, Matiddi et al. 2017), and these are also commonly encountered in floating marine litter (Di-Méglio \& Campana 2017 ,
Arcangeli et al. 2018). According to Suaria \& Aliani (2014), 62 million macro litter items are currently floating on the surface of the whole Mediterranean basin, temporarily accumulating in certain areas driven by ocean circulation dynamics and anthropogenic activities (Mansui et al. 2015). Sea turtles can move independently of currents, even as hatchlings (Bentivegna et al. 2007, Putman \& Mansfield 2015, Wildermann et al. 2017). Moreover, most of the preferred prey for sea turtles while they are in oceanic waters are macro-planktonic organisms, whose distribution is governed by currents. Therefore, it can be expected that there will always be zones of cooccurrence of marine debris and turtles attracted by the availability of food. The monitoring of floating macro litter can indicate marine litter accumulation areas and act as a proxy indicator of litter occurrence in the water column. Risk-exposure areas with high potential for interactions can then be identified as areas where marine litter accumulations overlap with the presence of marine species, such as sea turtles or cetaceans (Darmon et al. 2017, Di-Méglio \& Campana 2017, Campana et al. 2018), for which marine litter could be a potential threat.

Our study aimed to overcome the absence of continuous data on sea turtle occurrence in oceanic regions of the Mediterranean by collecting and analysing data from at-sea surveys of sea turtles along fixed-line transects covering the Western Mediterranean and the Adriatic Sea. For this, we made use of regular passenger ferries that host expert observers and allow low cost at-sea surveys at different times of the year and over long time spans. This method has already proven to be successful in monitoring longterm cetacean presence in the Mediterranean Sea (e.g. Arcangeli et al. 2013) at a seasonal time scale (e.g. Arcangeli et al. 2017) and is likewise suitable for observing other marine megafauna. In addition, by contemporaneously collecting data on floating marine litter items, another aim of this study was to identify areas and seasons in which sea turtles are most exposed to this widespread threat in the Mediterranean.

\section{MATERIALS AND METHODS}

\subsection{Study site}

Sea turtle and marine litter monitoring was carried out along 8 trans-border transects covering the Mediterranean Sea within the latitudes $43.6^{\circ} \mathrm{N}$ and $36.6^{\circ} \mathrm{S}$ and connecting Toulon-Ajaccio, Livorno- 
Bastia, Livorno-Gulf of Aranci, CivitavecchiaBarcelona, Palermo-Civitavecchia-Tunis, CagliariPalermo, and Ancona-Igoumenitsa-Patras. This network of fixed line transects is representative of most of the Western Mediterranean Sea, excluding the Alboran and Algerian Seas, and of most of the Adriatic Sea, excluding the very northern part. The transects run through both known pelagic foraging and developmental habitats for juvenile and adult turtles and areas that are expected to host turtles, but for which observation data are still lacking. The area is also particularly important because the probability of interaction between biota and litter is very high (Arcangeli et al. 2018). Sampled transects were chosen in order to cross potential low-/high-density areas for both sea turtles and litter, and were almost perpendicular to expected density gradients (e.g. migration routes, gradient of litter pollution from coast to high sea areas), and covering a wide range of ecological conditions (Evans \& Hammond 2004, Galgani et al. 2013).

\subsection{Sample collection}

The use of ferries as observation platforms allowed for cost-effective repeated sampling along the same transects, even in the high sea areas which are usually difficult to reach with smaller research vessels, and during all seasons (Zampoukas et al. 2014). Surveys were performed on a seasonal basis with at least 3 surveys per season along each sampling transect. Seasons were defined as winter: January to March; spring: April to June; summer: July to September; and autumn: October to December. Data on loggerhead turtles were systematically collected beginning in 2013 using a standard protocol specifically developed for marine biota monitoring along fixed sampling transects from large vessels (ISPRA 2015a; Technical Annex I, Arcangeli et al. 2014). Simultaneously, data on floating marine macro litter (over $20 \mathrm{~cm}$ size) were collected using a standard protocol that conformed to the guidelines compiled by the MSFD technical subgroup (Galgani et al. 2013) and specifically developed for collecting data from ferries (ISPRA 2015b; Technical Annex II, Arcangeli et al. 2018). According to the methodology, the ferries provided an observation point at 20-29 m height and travelled at a mean speed in the range of 19-25 knots. Two experienced observers conducted the marine fauna monitoring by being positioned on the 2 sides of the command deck and scanning both sides of the ship within an angle of $130^{\circ}$ ahead in order to avoid re-counting the animals.
An additional dedicated observer monitored floating marine litter. In order to overcome perception bias, all observers undertook a training period with senior observers before being admitted to the monitoring programme. Moreover, monitoring was carried out during daylight hours only in optimum weather conditions (" 3 on the Beaufort scale for sea turtles and " 2 for marine litter protocols). The observations were made by the naked eye, with the support of binoculars and digital cameras to correctly identify the species and the number of animals or, in the case of litter, to confirm the type and/or the material of items. Two dedicated GPSs were used for automatically recording the survey track at the finest resolution, marking the beginning/ending points and the locations of sea turtles and floating items. According to the floating litter monitoring method, a fixed strip width (Thiel et al. 2003, Pyle et al. 2008, Topcu et al. 2010) and the side of the ship with better visibility was defined at the beginning of the effort (for details on the methodology, see Arcangeli et al. 2018). The identification and categorisation of items were based on the type of material (artificial polymer materials, glass, processed wood, metal, textile, paper, rubber, natural debris) and then assigned to subcategories ('General Name') according to the MSFD guidance Master List (Galgani et al. 2013); for the purpose of this study, however, we used the information on the artificial polymer aggregated at a material level, to identify seasonal accumulation areas where sea turtles are most exposed to the risk of entanglement or ingestion. Given the mean height of the ferries, only items larger than $20 \mathrm{~cm}$ were recorded, since only items of this size can reliably be seen within the detection strip and also because this size comprises several common litter items and can be used as an indicator of marine litter presence, including smaller items and litter in the water column.

\subsection{Data analysis}

For the purposes of the study, the area was divided into the following 8 subareas (Fig. 1): Adriatic Sea (AS), Ionian Sea (IS), Corsica Sea (CS), Ligurian Sea (LS), Sardinia-Balearic Sea (SB), Bonifacio strait (Bon), Tyrrhenian Sea (TS), and Sardinia-Sicilian Channels (SSCC).

Inter- and intra-annual analyses were performed, normalizing the records by effort, using each single survey transect as a statistical unit. To analyse the distribution of both sea turtles and marine litter, a grid with $5 \mathrm{~km}^{2}$ cells was overlaid on the study area, assigning each cell to the corresponding subarea, 


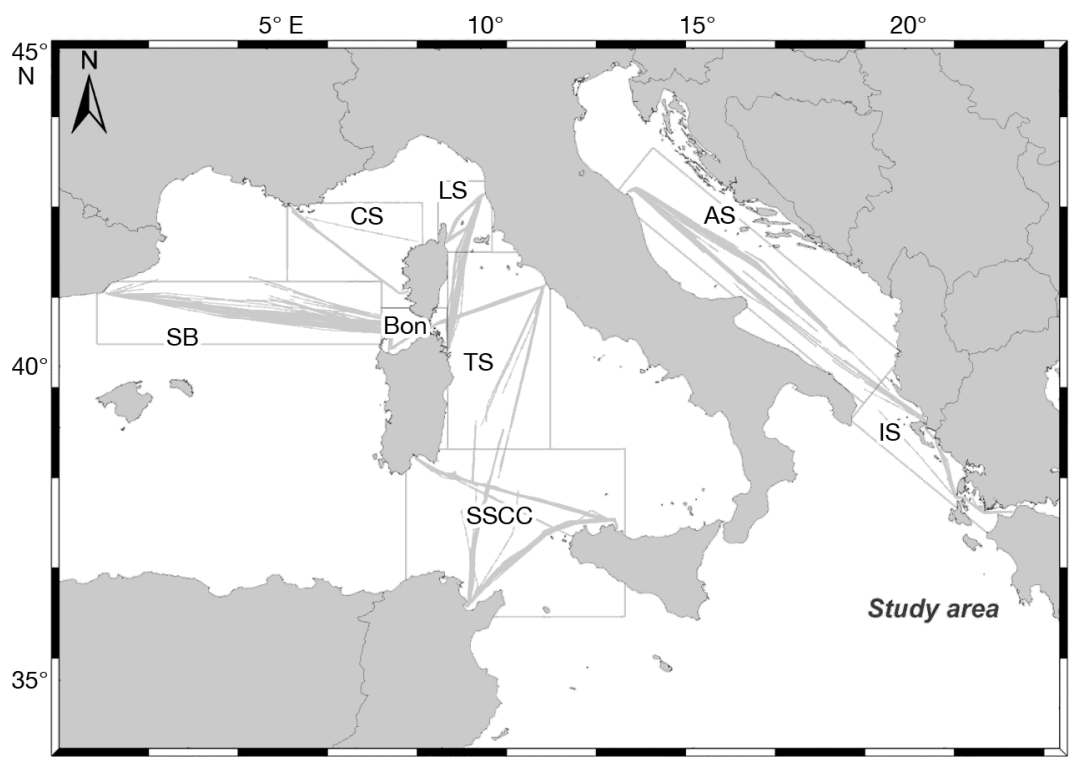

Fig. 1. Effort performed along the surveyed transects. The boxes correspond to the subareas used for spatial comparison of the different basins: Adriatic Sea (AS), Ionian Sea (IS), Corsica Sea (CS), Ligurian Sea (LS), Sardinia-Balearic Sea (SB), Bonifacio Strait (Bon), Tyrrhenian Sea (TS), Sardinia-Sicilian Channels (SSCC) sea turtle analysis. The SPUE $_{\text {cell }}$ was calculated for all data pooled together and for each season separately. A preliminary clustering analysis was performed using Moran's $I$ and average nearest neighbour analyses to test if the distribution of sightings followed a clustered or spread/random pattern. Kernel density estimation (KDE) was then performed on the basis of the SPUE $_{\text {cell, }}$ using a search radius of $50 \mathrm{~km}$, to show the areas of highest probabilities of sea turtle occurrence in the different seasons. The Getis-Ord Gi* analysis (Getis \& Ord 1992) was then used to identify locations of statistically significant hot spots, considered as areas where cells with high sighting values were spatially clustered; for this study, only the most significant values $(>2.58$ or $<-2.58 \mathrm{SD})$ were used for displaying the more intense hot/cold clusters (Arcangeli et al. 2017).

\subsubsection{Floating marine litter} grids, only the cells with at least 1 track-line of effort (separately for sea turtles and for marine litter) were selected and, to account for uneven effort, a minimum total effort per cell was set at $10 \mathrm{~km}$.

Statistical differences for both sea turtles and marine litter were investigated using the non-parametric Kruskal-Wallis (KW) test with Bonferroni correction and a post hoc pairwise comparison with the MannWhitney (MW) $U$-test testing the hypothesis of equal medians among samples. Statistical analyses were performed using the software Past 2.17 (Hammer et al. 2001).

\subsubsection{Sea turtles}

Sea turtle records were firstly investigated by year and season. The sighting rate, i.e. sightings per unit effort (SPUE), was used as a proxy index of sea turtle abundance to compare potential changes over time, and was calculated as: SPUE $=(\mathrm{N} / \mathrm{km}) \times 100$, where $\mathrm{N}=$ number of animals sighted, and $\mathrm{km}=$ distance travelled per effort in good weather conditions. To study sea turtle distribution, the SPUE per cell was used as the statistical unit and calculated as $\mathrm{SPUE}_{\text {cell }}=$ (sightings per cell $/ \mathrm{km}$ of effort within each cell) $\times$ 100. Of the entire grid of 3378 cells, we selected 3371 cells with a minimum sample effort of $10 \mathrm{~km}$ for the
The amount of plastic recorded simultaneously with the turtle survey in the different subareas and in the different seasons was estimated as a percentage of the total litter items. The amount of plastic was then normalized by accounting for strip width, and calculated as density $(D)=\mathrm{n} /(w \times l)$ with $\mathrm{n}=$ number of items observed, $W=$ width of the observed strip, and $l=$ length of the surveyed transect Shiomoto \& Kameda 2005). The spatial distribution of plastic density was analysed using the KDE to highlight areas of plastic accumulation over the different seasons (Arcangeli et al. 2018). The records of plastic items were initially analysed separately to highlight whether data showed random patterns or clusters of accumulation as with the sea turtle distribution analysis. Using the spatial tools in ArcGIS, a buffer was built around each effort track corresponding to the transect width. The buffered tracks were associated within the intersected cells and pooled together using the 'Dissolve' tool in ArcGIS, and the density values of litter were calculated for the total surveyed area within each cell. Based on the density value per cell, the KDE was then performed and the isopleths corresponding to $90 \%$ of the total values of the entire region were obtained for each season $(\mathrm{km})$ (Matsumura \& Nasu 1997, Thiel et al. 2003, 
to highlight the areas of highest litter accumulation. As for the hot spots of loggerhead turtles, the GetisOrd $\mathrm{Gi}^{*}$ analysis (Getis \& Ord 1992) was then used to identify the statistically significant areas of plastic item accumulation.

\subsubsection{Risk exposure}

In order to identify the high risk exposure areas where sea turtles are most likely to encounter plastic items, a buffer around sea turtle sightings was built with a radius of 2 and $10 \mathrm{~km}$ (Darmon et al. 2017). The number of floating plastic pieces $(>20 \mathrm{~cm})$ falling within the buffered areas were then counted, in order to highlight the percentage of animals exposed to plastic and the number of items surrounding the individuals. Then, given the fact that exposure changes with season, depending on both the occurrence of the sensitive species and the concentration of the threat (i.e. plastic items), seasonal KDEs of loggerhead turtles and floating plastic were overlaid and a new raster was created aggregating the density values of both the hot spots of loggerhead turtles and the highest concentration of floating litter, in order to display the areas with the highest combined values. The KDE raster data of loggerhead turtles and litter were first reclassified in order to exclude the lowest class of density values, and then the 2 rasters were aggregated, resulting in a combined density index of sensitive species and threat. Moreover, the percentage of sightings within the isopleths of 0.9 (Campana et al. 2018) plastic density and with >0.03 plastic items $\mathrm{km}^{-2}$ were then calculated as a seasonal indicator of the probability of loggerhead turtles encountering litter. Unless otherwise indicated, results are presented as means $\pm \mathrm{SE}$.

\section{RESULTS}

\subsection{Sea turtles}

From 2013 to 2017, 1004 surveys were performed to monitor sea turtles during all seasons along the surveyed transects in the Mediterranean Sea, totalling $183567 \mathrm{~km}$. During the study period, 1106 sightings occurred, with more animals sighted at the same time in some observations, resulting in a total of 1258 specimens of loggerhead sea turtles recorded along all monitored transects. On average, 0.6 individuals for $100 \mathrm{~km}$ of effort were detected for all areas and seasons pooled.

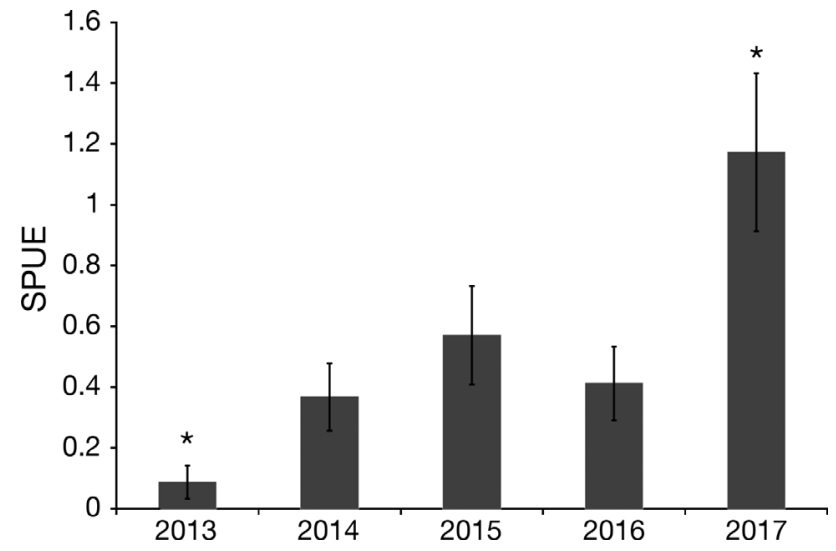

Fig. 2. Loggerhead turtle sightings per unit effort (SPUE) recorded during the years of the study on a total of $188567 \mathrm{~km}$ of effort ( $\mathrm{N}=1258$ individuals). Error bars represent SE. Asterisks show the 2 years that were significantly different

When considered on an annual basis, the highest sighting rate was recorded during the last survey year (2017) with an SPUE of $1.2 \pm 0.2$, while the lowest was detected during 2013 (0.09 \pm 0.05 ; MW, p < 0.001; Fig. 2). The increased sighting rate recorded during 2017 was mainly driven by the significantly higher SPUEs detected in the north-western subareas of Sardinia-Balearic (2017 significantly different from the previous years; MW, p < 0.001) and Ligurian Seas (2017 significantly different from 2014; MW, p < 0.01). No other subareas showed any statistically significant inter-annual differences, although we observed a marked annual oscillation of SPUEs in the Sardinia-Sicilian Channels and the Tyrrhenian Sea.

After stratifying the data by subareas and pooling all seasons together, the Sardinia-Sicilian Channels showed the highest sighting rate for loggerhead turtles compared to all other subareas, on the order of 9fold higher $(\mathrm{SPUE}=2.6 \pm 0.4 \mathrm{SE} ; \mathrm{MW}, \mathrm{p}<0.001)$. The significantly lowest SPUE values were recorded in the Sardinia-Balearic and Ligurian Seas and in the Bonifacio subarea $(<0.12$ SPUE; $p<0.01)$, while the Adriatic, Ionian, Tyrrhenian, and Corsica Seas showed similar SPUEs between 0.3 and 0.25 sightings per $100 \mathrm{~km}$.

The results on seasonality showed an increase in the sighting rates during spring and summer in the majority of the investigated subareas: spring and summer showed significantly higher SPUEs (0.35 \pm 0.06 and $0.7 \pm 0.13$, respectively) than autumn/winter $(0.14 \pm 0.04$ and $0.1 \pm 0.03 ; \mathrm{MW} \mathrm{p}<0.001)$. Stratified data for each subarea showed different variability in the species occurrence: in most of the subareas, significantly higher sighting rates were recorded during spring and/or summer (MW, p < 0.01), while no seasonal differences emerged in the Adriatic, Ionian, and Corsica Seas, and in the Bonifacio subarea (Fig. 3). 


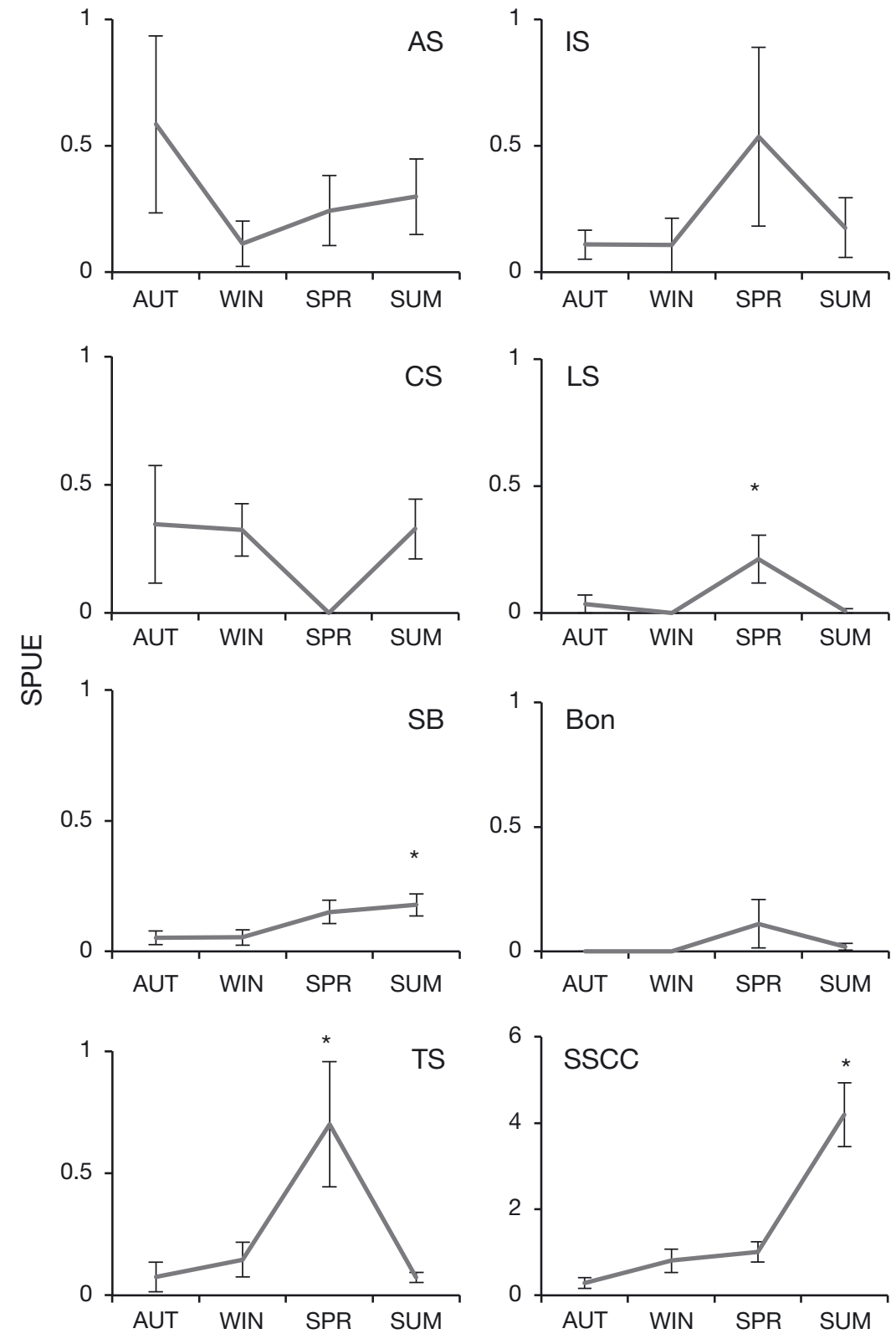

Fig. 3. Seasonal variability of loggerhead turtles detected in the different subareas of the study (abbreviations as in Fig. 1). An abundance index (sightings per unit effort, SPUE) is shown on the $y$-axis. Asterisks indicate statistical significance $\left({ }^{*} \mathrm{p}<0.01\right)$; error bars represent SE. Note the difference in scale between the SSCC panel and all other panels. AUT: autumn; WIN: winter; SPR: spring; SUM: summer

The spatial analysis showed a patchy distribution of loggerhead sea turtles, where cells with higher sighting values were particularly concentrated in the area of the Sicilia-Sardinian Channels (Fig. 4). Fig. 5 also shows the areas with a higher probability of loggerhead presence highlighted by the kernel analysis and the statistically significant hot spots that emerged by the Getis-Ord $\mathrm{Gi}^{*}$ analysis. Hot spots of logger- head presence are highlighted during all seasons in the central Adriatic Sea, and during spring and autumn more to the south, along the eastern coast of the Ionian Sea. In the western Mediterranean Sea, the most extensive hot spots emerged in the area of the Sardinia-Sicilian Channels during all seasons, with a higher concentration of hot spot cells during spring and summer, extending towards the central Tyrrhenian Sea during spring, and being mostly concentrated in the Sardinian channel during summer. Looking at the northern latitudes, some hot spot areas emerged in the SardiniaBalearic basin especially during spring and summer. Few temporary areas also appeared around the Bonifacio subarea and in the Corsica Sea.

\subsection{Floating marine litter}

Plastic items accounted for the highest percentage of items detected, ranging from $80 \%$ up to almost $95-97 \%$ in the Corsica and Ligurian subareas. The amount of plastic appeared to be highest in all seasons in the Adriatic Sea, with no statistical difference among seasons. The other subareas showed a significantly higher accumulation of plastic highlighted by the Getis-Ord $\mathrm{Gi}^{*}$ analysis during spring and/or summer, particularly in the Ligurian Sea, and during autumn mainly near more coastal areas of Corsica, Spain, and Tunisia (Fig. 6).

\subsection{Risk exposure}

Considering all seasons and areas pooled together, $70 \%$ of animals were within a $2 \mathrm{~km}$ radius of plastic items (85\% within a $10 \mathrm{~km}$ radius): a mean of $2.7 \pm 0.1$ plastic items, up to a maximum of 16 items, surrounded the turtles within a radius of $2 \mathrm{~km}$, while, when considering a radius of $10 \mathrm{~km}$, a mean of $18 \pm 0.4$ up to a maximum of 118 items surrounded the animal.

Combining areas of higher probability of loggerhead sea turtle presence and areas with the highest 


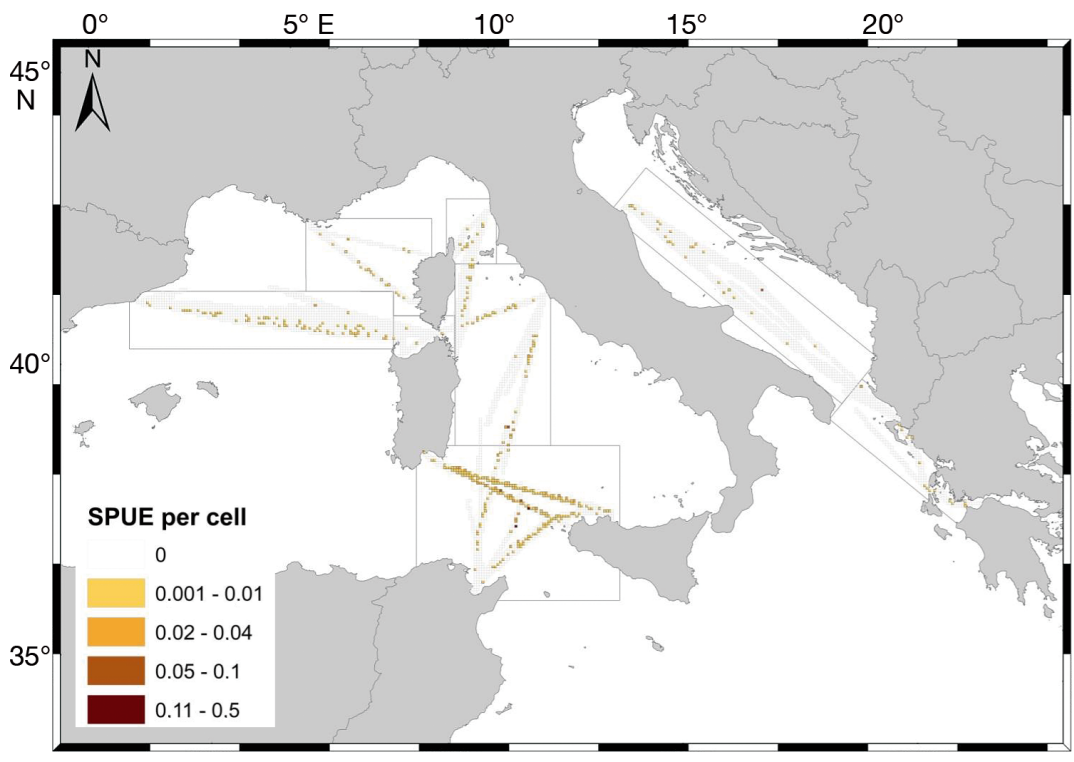

Fig. 4. Spatial distribution of the abundance index (sightings per unit effort, SPUE) of loggerhead sea turtles in the monitored areas. The grey rectangles indicate the areas with a minimum sample effort of $10 \mathrm{~km}$. All data are pooled together accumulation of plastics, areas of higher exposure to risk emerged in the Adriatic Sea during all seasons and were highlighted during spring in the Sardinia-Balearic Sea, and during summer in the Sardinia-Sicilian Channels (Fig. 7). Spring and summer were generally the seasons in which sea turtles were most exposed to the risk of encountering plastic litter, when almost $5 \%$ of total turtle sightings were recorded within the most polluted areas. Indeed, as illustrated in Fig. 8, the number of floating plastic items surrounding the turtles in a radius of 2 or $10 \mathrm{~km}$ is significantly higher during spring and summer ( $>1$ for $2 \mathrm{~km}$; $>9$ for $10 \mathrm{~km}$ ) than during autumn and winter (MW, p < 0.01). Animals surrounded by a higher number of plastic pieces than the seasonal mean were found in

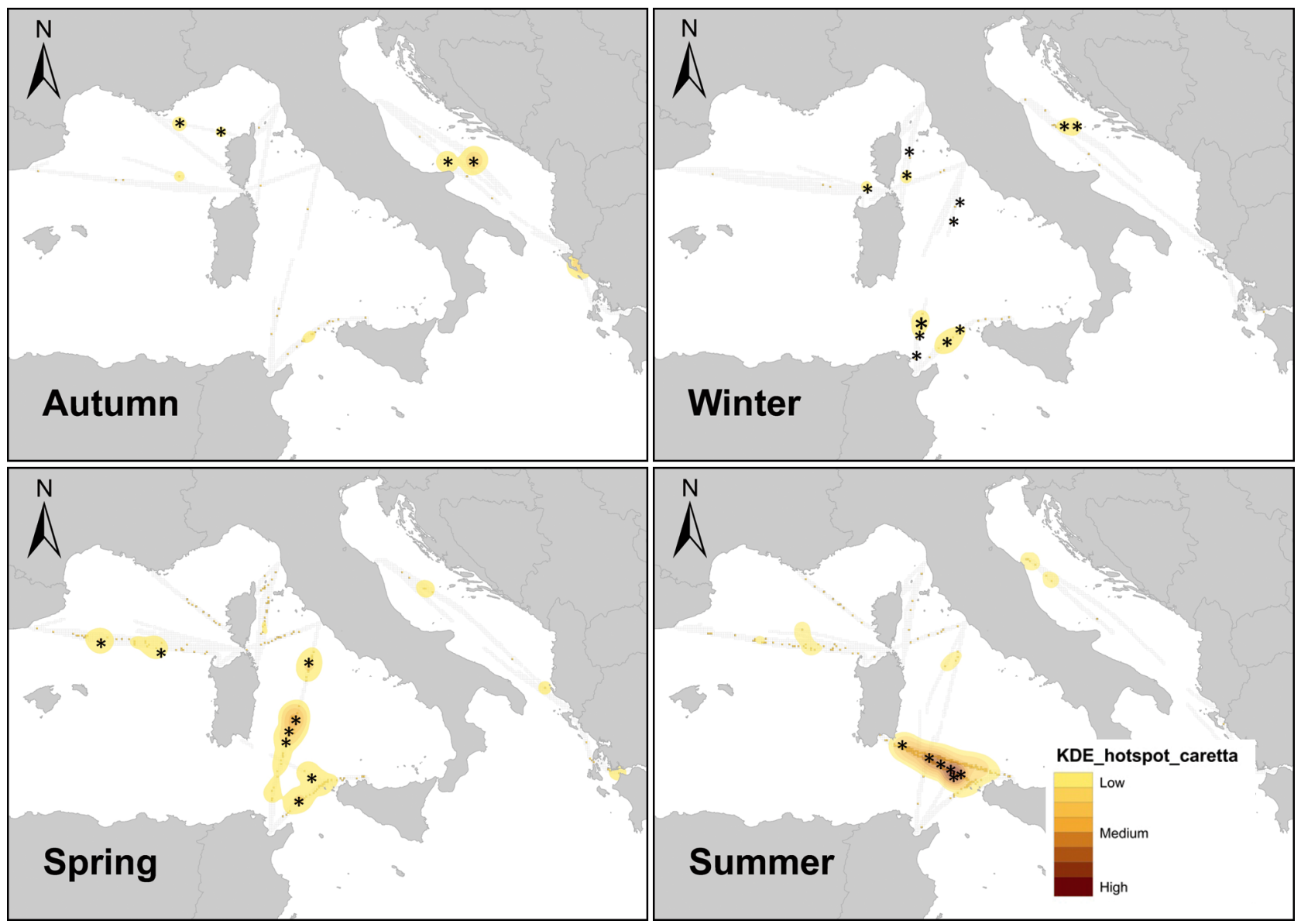

Fig. 5. Areas of seasonal hot spots of Caretta caretta identified by the kernel analysis (kernel density estimation; KDE) based on the index of abundance (sightings per unit effort, SPUE). Black asterisks indicate significant accumulation areas determined by the Getis-Ord $\mathrm{Gi}^{*}$ analysis. All seasonal data are pooled together 


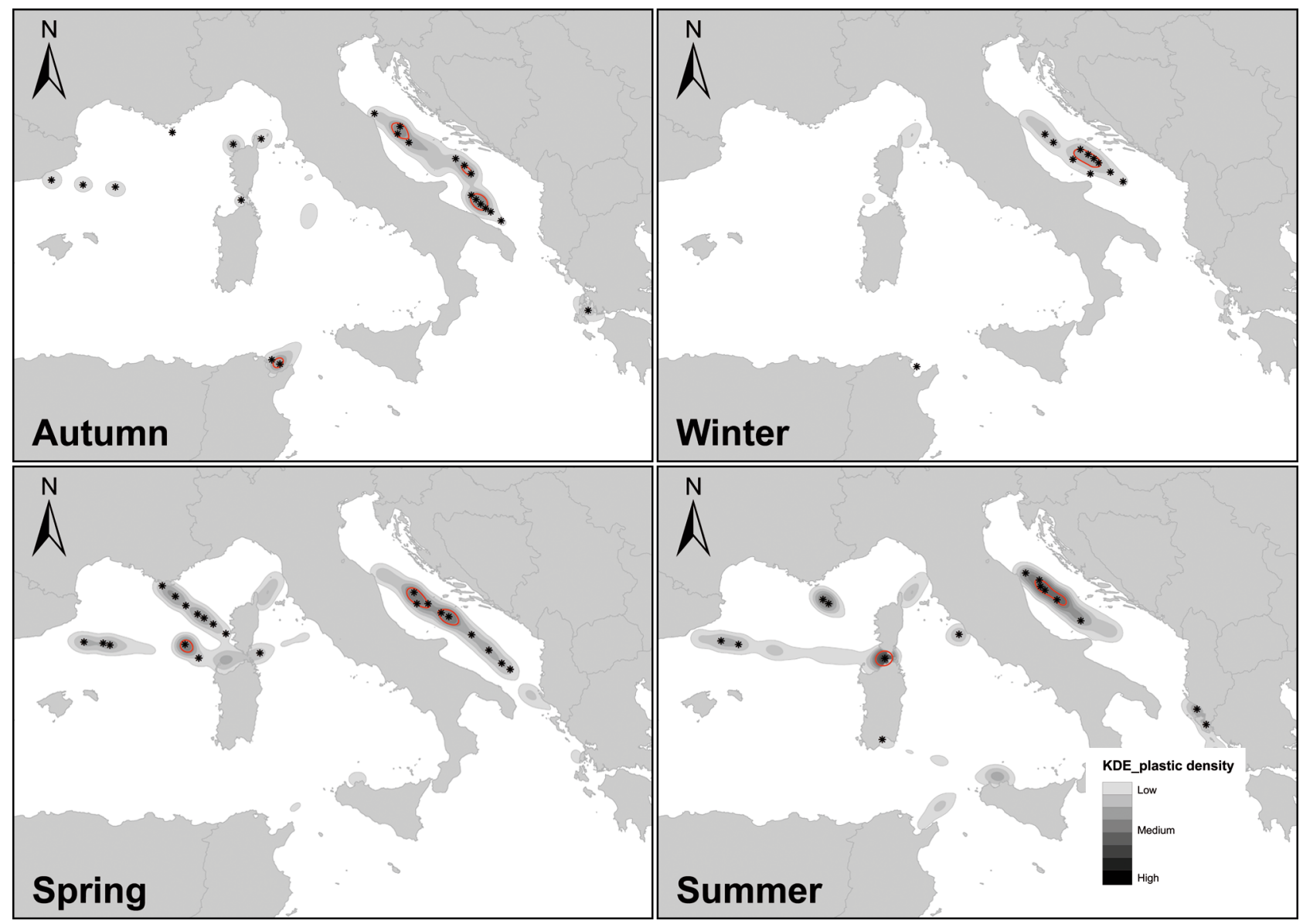

Fig. 6. Seasonal accumulation areas of plastic highlighted by kernel analysis (kernel density estimation; KDE). The red ellipses indicate the $90 \%$ isopleth. Asterisks indicate significant accumulation areas identified by the Getis-Ord Gi* analysis. All seasonal data are pooled together

almost all areas highlighted by the kernel analyses, concentrating in the Adriatic Sea during winter and in the Sardinia-Sicilian Channels during summer.

\section{DISCUSSION}

\subsection{Sea turtle distribution}

Caretta caretta is currently listed as a priority species in the EU Habitats Directive 92/43/ CEE, but a recent review of current knowledge highlighted important gaps in terms of sea turtle distribution, habitat use, connectivity, migratory routes, and behaviour in the Mediterranean Sea (Casale et al. 2018). Indeed, assessors such as those evaluating the population status of species both in the IUCN Red List and in the Habitats Directive surveillance report are in urgent need of long-term data about the threats and abundance of sea turtles in foraging habitats, which were completely lacking for the Mediterranean subpopulation.

This study is the first repeated survey of sea turtle presence in the offshore areas of the Western Mediterranean, Adriatic, and Ionian Seas over 5 consecutive years. While our data make a potential contribution to such assessments, it has to be mentioned that we did not apply any correction factors for the availability bias during surveys, i.e. we did not account for turtles that were diving or underwater and hence not detectable at the surface (Fuentes et al. 2015). To calculate actual turtle numbers from ship surveys, it is necessary to know the percentage of time a turtle spends underwater (i.e. to account for turtles not seen at the water surface). Yet this is likely to be a highly variable behavioural parameter, which among other reasons, depends on water temperature, the habitat being used by the turtle (pelagic vs. benthic), and what the habitat is being used for (e.g. foraging or migrating through), the size of the turtle, and the avail- 


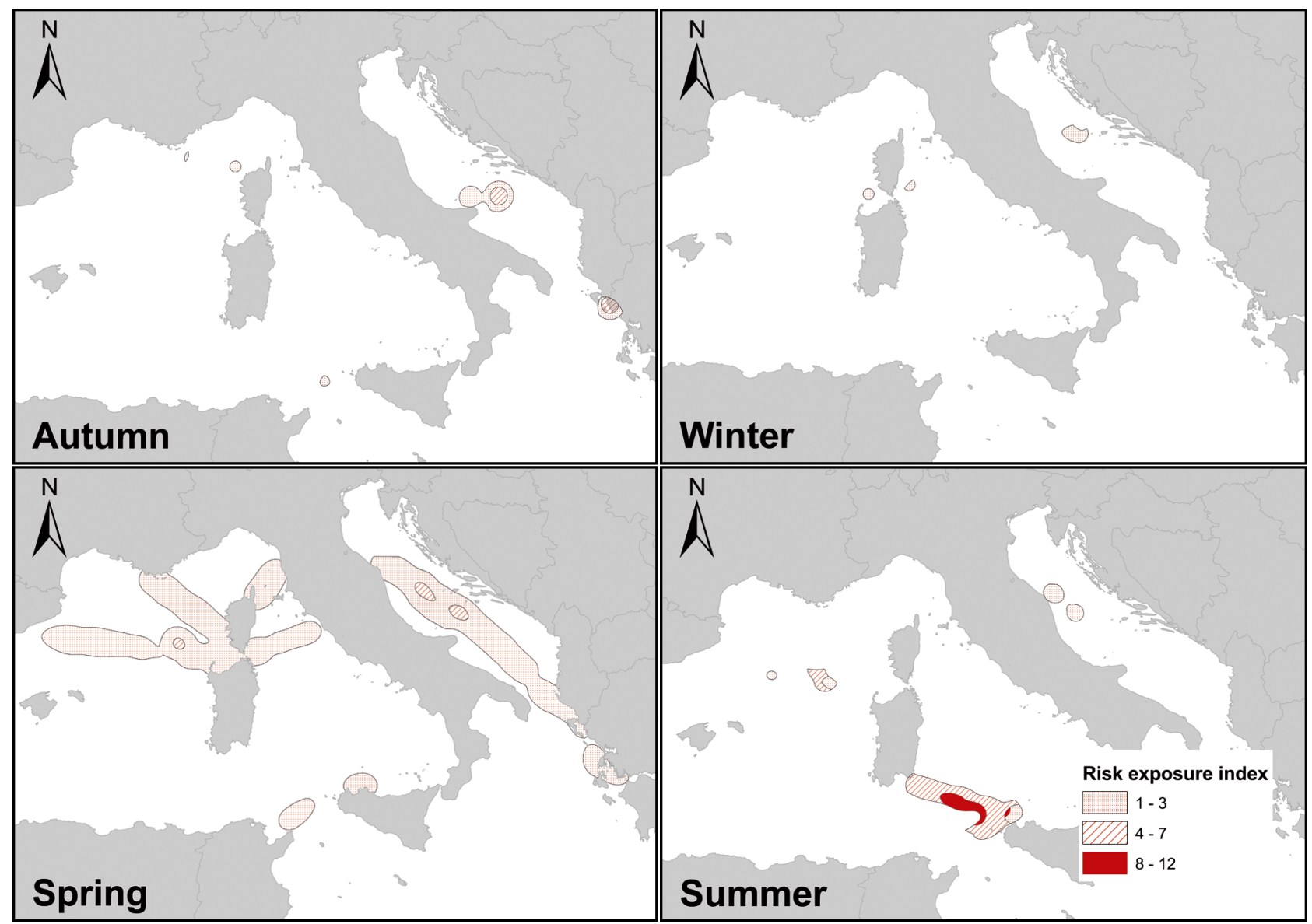

Fig. 7. Areas at higher risk of exposure to macro litter identified by the combined seasonal hot spot areas of loggerhead turtles and the highest accumulation of plastic items. All seasonal data are pooled together

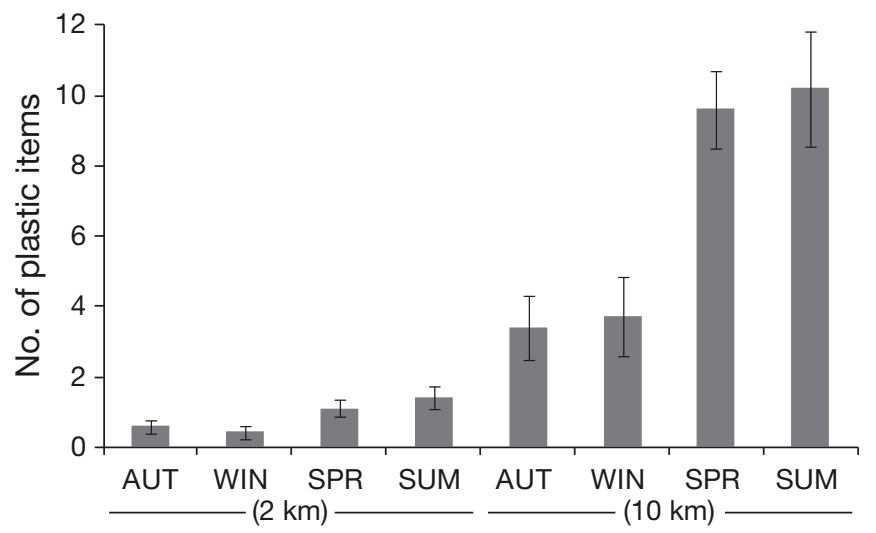

Fig. 8. Seasons with higher risk of exposure to macro litter based on the number $( \pm \mathrm{SE})$ of plastic items surrounding a sea turtle within a radius of 2 and $10 \mathrm{~km}$ in different seasons.

AUT: autumn; WIN: winter; SPR: spring; SUM: summer

ability of suitable prey (Hochscheid et al. 2007a,b, 2010). Ideally, a suite of correction factors which take these variations into account should have been applied, but at the current state of knowledge these data are not available and cannot be applied realistically to such vast spatial and temporal surveys. However, to monitor changes in population size for many conservation purposes, it may not be necessary to have absolute population estimates, especially if the species is highly mobile and distributed heterogeneously spatially and/or temporally. Instead, changes in population size can be inferred from trends in a sightingbased index that is itself related to abundance (e.g. Vorisek et al. 2008). Therefore, here we presented only abundance indices, which are lower than actual turtle densities, but are comparable over both the temporal and spatial scales of our study.

Results of the present study showed a significant spatio-temporal variation in turtle SPUE, highlighting the importance of continued repeated surveys on turtle presence, since estimates based on only 1 year or with limited geographical coverage can be greatly biased and lead to unrealistic population trend analyses. This is the case for the significant increase recorded in 2017 that was mainly limited to north-west- 
ern subareas, and whose significance needs to be ascertained by additional surveys in the following years. However, even if the $5 \mathrm{yr}$ monitoring period was sufficient to reveal inter-annual differences in turtle sightings, it is yet premature to conclude on any trends, notwithstanding the significant increase in turtle presences between 2013 and 2017. Continued monitoring along the same fixed transects will be able to provide additional sets of 5 yr of data on turtle sighting trends in the same area, to which the current results can then be compared.

Other than inter-annual variation in the turtle abundance index, our frequently repeated surveys also revealed seasonal differences, which were consistent over the years in some regions. The general picture suggests a south-eastward shift in turtle presence during autumn/winter, whereas the northern and westernmost regions (Ligurian Sea and the area between Sardinia and the Balearic Archipelago) are mostly used in the spring and summer period. These seasonal differences could in part be due to different surfacing behaviour between summer and winterturtles are more active during the warmer months and tend to be seen more frequently at the water surface where they replenish their oxygen stores after extensive underwater activities. In winter, they undergo long and extended periods either resting in midwater or on the sea floor and return to the surface much less frequently, sometimes at intervals of up to several hours (Hatase et al. 2007, Hochscheid et al. 2007a). Nevertheless, our findings are consistent with the reduced number of sightings recorded in winter by aerial surveys in the Ligurian sea (Lauriano et al. 2011) and with recent studies in which turtles have been reported to undergo seasonal migrations to avoid cold water temperatures in the winter period. There is a documented north-southwards movement in the Adriatic Sea, and some satellite tracking studies have shown that turtles tended to leave the Ligurian and also the Tyrrhenian Sea to overwinter in the eastern Mediterranean (Bentivegna 2002, Zbinden et al. 2011, Luschi et al. 2013, Luschi \& Casale 2014).

Looking at the general distribution of turtles throughout the study area, a clear picture of the most frequented areas emerged, which included the Adriatic Sea, one of the most important foraging habitats for loggerhead turtles. It must be acknowledged, however, that some differences in data between areas may be due to the different times of day that single transects were surveyed, although the extent to which this occurs is difficult to assess. This is because little is known about the proportion of time that turtles spent at the surface at different times of the day. A recent study by Freitas et al. (2019) showed that pelagic juvenile loggerhead turtles frequent the upper 0 to $1 \mathrm{~m}$ layer more often during the day than during the night, but no variations in surfacing during daylight hours (i.e. from dawn to dusk) were reported. This would suggest similar encounter rates on all transects considering that they were all performed in daylight. It must also be noted that the monitored transect in the Adriatic Sea passes through the middle of the basin and does not extend all the way to the north of the basin, where most of the turtles reside, at least during the summer months (Lazar et al. 2002, Fortuna et al. 2018). As such, the Adriatic transect passes only through the known southern pelagic habitat which has been identified for juvenile loggerhead turtles, and possibly also for green sea turtles Chelonia mydas (Margaritoulis et al. 2003, Lazar et al. 2004, Casale et al. 2012, Fortuna et al. 2018). Also, the Tyrrhenian Sea, especially the southern triangle between Sardinia, Tunisia, and Sicily, showed conspicuously high turtle abundance indices. The higher SPUE of the southern Tyrrhenian Sea compared to that of the Adriatic Sea was rather unexpected, since the Tyrrhenian Sea has thus far not received much consideration as an important marine habitat (see also Casale \& Mariani 2014 for a discussion on this topic). Only recently, Luschi et al. (2018) identified a high-use area in the north-central Tyrrhenian, derived from satellite tracking results on 8 adult-sized loggerhead turtles. Our results could not confirm this finding, because no effort was made through this part of the Tyrrhenian Sea. However, given that loggerhead turtle presence has also been reported from the Aeolian Archipelago north of Sicily (Blasi \& Mattei 2017), it is probable that the Tyrrhenian Sea hosts more loggerhead turtles than previously estimated and may indeed be an important foraging area for both juveniles and adult turtles. Also, the preliminary results of the basin-wide ACCOBAMS aerial surveys performed during summer 2018 (ACCOBAMS Survey Initiative, www.accobams.org/mainactivites/accobams-survey-initiative-2/asi-preliminaryresults/) showed a high occurrence of sea turtles in the central-southern Tyrrhenian Sea in accordance with our findings, and confirmed the mostly centralnorthern distribution of the species in the Adriatic Sea. Moreover, the south Tyrrhenian triangle is a passageway not only into the Tyrrhenian Sea itself but also between the Western and the Eastern Mediterranean, connecting the 2 basins through the Strait of Sicily. Several satellite tracking studies have documented this (Bentivegna 2002, Eckert et al. 2008, Luschi et al. 2013), as have numerical simulations of 
particle distribution that highlight exchange of turtles drifting passively between the 2 basins (Casale \& Mariani 2014, Maffucci et al. 2016).

In summary, by comparing distribution and sighting rates over different seasons in pelagic areas of the Mediterranean basins, findings of our study confirmed well known important areas for loggerhead sea turtles, such as the Adriatic Sea, over all study years, pointed out the importance of new areas that were recently assumed to be significant for the species, and sustained the migration pattern hypostasized by other studies.

\subsection{Distribution of floating marine litter}

As confirmed in previous studies, plastic items made up the highest proportion of drifting macro litter. Our study was based on a reanalysis of the artificial polymer fraction of the same data set used by Arcangeli et al. (2018), extended by a further 2 yr of surveys, and confirmed the general distribution patterns reported in that study. In brief, floating plastics tend to accumulate and re-circulate in the semi-closed basin of the Adriatic Sea, which receives high inputs from coastal activities and rivers, hence the high and year-round densities. Peak densities of plastic material during the spring and summer months in the Ligurian Sea, Sardinian-Balearic Seas, and the Bonifacio subarea are a combined result of seasonally varying surface circulations and increased anthropogenic activities, such as tourism, maritime traffic, and fishing (see Arcangeli et al. 2018 and references therein).

\subsection{Risk exposure}

The distribution of floating plastic items is predominantly driven by surface currents, whereas sea turtles can move independently of currents from very young ages (Bentivegna et al. 2007, Putman \& Mansfield 2015, Wildermann et al. 2017). However, the distribution of macro-planktonic organisms, such as jellyfish and salps, the preferred prey on which turtles forage in the open sea, is also governed by currents, so it can be expected that there will always be zones of co-occurrence of marine debris and food for turtles, and hence, these zones will attract the turtles themselves. By overlaying the distributions of sea turtles and plastic items in the study area, we were able to identify several areas, both permanent and seasonal, where turtles have a higher probability of exposure to floating plastic debris. Particularly out- standing was the Adriatic Sea, where floating plastic was found in all seasons in the same areas with higher probabilities of turtle presence. In other areas, i.e. the Sardinian-Balearic Seas and the SicilySardinia Channel, the risk of exposure changes with season. Overall, spring and summer were identified as the seasons with the highest amount of litter in the areas with sea turtles, although litter was more diffuse during spring and more concentrated in specific areas during the summer. In the north-western Mediterranean Sea region, our findings confirm the critical area already identified by Darmon et al. (2017) in the Sardinia-Balearic area during summer and the area of high accumulation of litter in the western Ligurian Sea both in winter and summer.

It is not yet fully understood what drives turtles to ingest plastic items, and what proportion of the items is voluntarily vs. accidentally ingested. One widely disseminated explanation is that turtles mistake plastic bags for jellyfish (Schuyler et al. 2014), which would account for the high proportion of sheet-like plastic types found in turtles' gastrointestinal tracts (Campani et al. 2013, Matiddi et al. 2017). However, video footage taken by a camera mounted on a turtle's back showed that the turtle actually evaded a plastic bag floating singly in the water column (Narazaki et al. 2013). In any case, apart from sheetlike plastic types, many other categories of plastic and other marine debris have been found in turtles' digestive tracts, which do not resemble any typical prey organisms (Wilcox et al. 2016). However, the biofilm growing on plastic litter items might release chemical cues similar to food and thus tempt turtles to feed on them. For now, the question of why they are ingested remains unanswered. An increased exposure to marine litter puts an animal at higher risk of being impacted, although predation behaviour is poorly investigated, particularly with regard to whether litter is density dependent or not. More importantly, floating debris is not only a problem because of ingestion and the transfer of toxic chemicals present on the plastic items (Teuten et al. 2009), but it also poses a greater risk through entanglement (Duncan et al. 2017), which compromises the swimming and diving ability of turtles and possibly also their respiration when debris obstructs the nares and beak.

The marine litter problem is best tackled through prevention actions that reduce inputs (see Top 10 list by Gold et al. 2013, Rochman 2016, Cordier \& Uehara 2019). With respect to this, the European Parliament and the Council of the European Union have recently reached a provisional political agreement on new EU-wide rules proposed by the Commission to con- 
front marine litter at its source, targeting the 10 plastic products most often found on beaches as well as abandoned fishing gear (http://europa.eu/rapid/pressrelease_IP-18-6867_en.htm). However, the effect of these actions will probably not be seen for a long time while up to $20 \mathrm{Mt}$ of plastic litter continues to be introduced into the sea annually (Vannela 2012), of which the Mediterranean accumulates high loads (Cózar et al. 2015). In the meantime, current technological developments of direct litter removal systems could be set in place in the accumulation zones, especially those that were identified here as accumulation areas, once validated both for feasibility and economic sustainability (Cordier \& Uehara 2019).

\subsection{Concluding remarks}

To our knowledge, this is the first study using passenger ferries as platforms of observation for monitoring at-sea distributions and abundance of threatened loggerhead sea turtles in the Mediterranean Sea. The approach has proven successful for cost-effective long-term monitoring of marine megafauna, confirming abundant turtle encounters in already known foraging grounds and highlighting the existence of previously unreported zones of high sea turtle presence in the southern Tyrrhenian Sea. The detected seasonal variability supported the hypothesis of overwintering migration in the eastern Mediterranean, which has not yet been investigated. Also, the detected interannual changes in distribution with increasing encounter rate in the north-western subareas provided a useful baseline for future studies investigating potential climate-related changes. In addition, by contemporaneously collecting data on floating marine litter items, this method identified areas and seasons in the Mediterranean in which sea turtles are most exposed to this widely known hazard. The monitoring network of ferry lines is fairly well developed and established, especially in the study area, and is open to new partners that can contribute to increase the spatial coverage of the survey network, especially in the eastern Mediterranean Sea. Our study provides a solid baseline dataset that can be used to monitor inter-annual variations in sea turtle and floating marine litter presence and distribution in the western Mediterranean, Adriatic, and Ionian Seas. Constant monitoring of at least the threat-exposure areas identified here is necessary to control the development of these zones and to establish a basis for the evaluation of the effectiveness of applied measures, such as those foreseen by the EU directive.
Acknowledgements. This study was partially funded by the MEDSEALITTER project (co-financed by the European Regional Development Fund) and the MEDREGION project. We are thankful to all ferry companies participating in the research programme, especially to Corsica-Sardinia Ferries, Grimaldi Lines, Minoan Lines, and Tirrenia, who kindly hosted the researchers on board, and to all observers who participated in data collection on board. We thank the Editor and the reviewers, whose comments allowed us to greatly improve the quality of the manuscript.

\section{LITERATURE CITED}

Arcangeli A, Marini L, Crosti R (2013) Changes in cetacean presence, relative abundance and distribution over 20 years along a trans-regional fixed line transect in the Central Tyrrhenian Sea. Mar Ecol 34:112-121

Arcangeli A, Aissi M, Aragno P, Atzori F and others (2014) Cetaceans, marine birds, sea turtles, marine traffic and floating marine litter: potential of a synoptic multidisciplinary data collection in the western Mediterranean marine region. Biol Mar Mediterr 21:366-368 (in Italian with English abstract)

Arcangeli A, Campana I, Bologna MA (2017) Influence of seasonality on cetacean diversity, abundance, distribution and habitat use in the western Mediterranean Sea: implications for conservation. Aquat Conserv 27:995-1010

Arcangeli A, Campana I, Angeletti D, Atzori F and others (2018) Amount, composition, and spatial distribution of floating macro litter along fixed trans-border transects in the Mediterranean basin. Mar Pollut Bull 129:545-554

Avery-Gomm S, Borrelle SB, Provencher JF (2018) Linking plastic ingestion research with marine wildlife conservation. Sci Total Environ 637-638:1492-1495

* Bentivegna F (2002) Intra-Mediterranean migrations of loggerhead sea turtles (Caretta caretta) monitored by satellite telemetry. Mar Biol 141:795-800

*Bentivegna F, Valentino F, Falco P, Zambianchi E, Hochscheid S (2007) The relationship between loggerhead turtle (Caretta caretta) movement patterns and Mediterranean currents. Mar Biol 151:1605-1614

Blasi MF, Mattei D (2017) Seasonal encounter rate, life stages and main threats to the loggerhead sea turtle (Caretta caretta) in the Aeolian Archipelago (southern Tyhrrenian Sea). Aquat Conserv 27:617-630

*Biscoe DK, Maxwell SM, Kudela R, Crowder LB, Croll D (2016) Are we missing important areas in pelagic marine conservation? Redefining conservation hotspots in the ocean. Endang Species Res 29:229-237

* Camedda A, Marra S, Matiddi M, Massaro G and others (2014) Interaction between loggerhead sea turtles (Caretta caretta) and marine litter in Sardinia (Western Mediterranean Sea). Mar Environ Res 100:25-32

* Campana I, Angeletti D, Crosti R, Di Miccoli V, Arcangeli A (2018) Seasonal patterns of floating macro-litter across the Western Mediterranean Sea: a potential threat for cetacean species. Rend Lincei Sci Fis Nat 29:453-467

Campani T, Baini M, Giannetti M, Cancelli F and others (2013) Presence of plastic debris in loggerhead turtle stranded along the Tuscany coasts of the Pelagos Sanctuary for Mediterranean Marine Mammals (Italy). Mar Pollut Bull 74:225-230

Cardona L, Revelles M, Carreras C, San Felix M, Gazo M, Aguilar A (2005) Western Mediterranean immature loggerhead turtles: habitat use in spring and summer 
assessed through satellite tracking and aerial surveys. Mar Biol 147:583-591

Casale P (2015) Caretta caretta Mediterranean subpopulation. The IUCN Red List of Threatened Species 2015: e.T83644804A83646294. http://dx.doi.org/10.2305/IUCN. UK.2015-4.RLTS.T83644804A83646294.en (accessed 21 Oct 2019)

* Casale P, Mariani P (2014) The first 'lost year' of Mediterranean Sea turtles: dispersal patterns indicate subregional management units for conservation. Mar Ecol Prog Ser 498:263-274

Casale P, Affronte M, Scaravelli D, Lazar B, Vallini C, Luschi P (2012) Foraging grounds, movement patterns and habitat connectivity of juvenile loggerhead turtles (Caretta caretta) tracked from the Adriatic Sea. Mar Biol 159: 1527-1535

Casale P, Freggi D, Paduano V, Oliverio M (2016) Biases and best approaches for assessing debris ingestion in sea turtles, with a case study in the Mediterranean. Mar Pollut Bull 110:238-249

Casale P, Broderick AC, Caminas JA, Cardona L and others (2018) Mediterranean Sea turtles: current knowledge and priorities for conservation and research. Endang Species Res 36:229-267

Cordier M, Uehara T (2019) How much innovation is needed to protect the ocean from plastic contamination? Sci Total Environ 670:789-799

Cózar A, Sanz-Martín M, Martí E, González-Gordillo JI and others (2015) Plastic accumulation in the Mediterranean Sea. PLOS ONE 10:e0121762

Darmon G, Miaud C, Claro F, Doremus G, Galgani F (2017) Risk assessment reveals high exposure of sea turtles to marine debris in French Mediterranean and metropolitan Atlantic waters. Deep Sea Res II 141:319-328

* Di-Méglio N, Campana I (2017) Floating macro-litter along the Mediterranean French coast: composition, density, distribution and overlap with cetacean range. Mar Pollut Bull 118:155-166

Duncan EM, Botterell ZL, Broderick AC, Galloway TS, Lindeque PK, Nuno A, Godley BJ (2017) A global review of marine turtle entanglement in anthropogenic debris: a baseline for further action. Endang Species Res 34:431-448

Eckert SA, Moore JE, Dunn DC, Sagarminaga van Butten R, Eckert KL, Halpin PN (2008) Modelling loggerhead turtle movement in the Mediterranean: importance of body size and oceanography. Ecol Appl 18:290-308

Evans PGH, Hammond P (2004) Monitoring cetaceans in European waters. Mammal Rev 34:131-156

Fortuna CM, Cañadas A, Holcer D, Brecciaroli B and others (2018) The coherence of the European Union Marine Natura 2000 Network for Wide-Ranging Charismatic Species: a Mediterranean case study. Front Mar Sci 5:356

Freitas C, Caldeira R, Dellinger T (2019) Surface behavior of pelagic juvenile loggerhead sea turtles in the eastern North Atlantic. J Exp Mar Biol Ecol 510:73-80

Fuentes MMPB, Bell I, Hagihara R, Hamann M, Hazel J, Huth A, Marsh H (2015) Improving in-water estimates of marine turtle abundance by adjusting aerial survey counts for perception and availability biases. J Exp Mar Biol Ecol 471:77-83

Galgani F, Hanke G, Werner S, Oosterbaan L and others (2013) Guidance on monitoring of marine litter in European seas. MSFD Technical Subgroup on Marine Litter (TSG-ML)

*Getis A, Ord JK (1992) The analysis of spatial association by use of distance statistics. Geogr Anal 24:189-206

*Godley BJ, Blumenthal JM, Broderick AC, Coyne MS, Godfrey $\mathrm{MH}$, Hawkes LA, Witt MJ (2008) Satellite tracking of sea turtles: Where have we been and where do we go next? Endang Species Res 4:3-22

Gold M, Mika K, Horowitz C, Herzog M, Leitner L (2013) Stemming the tide of plastic marine litter: a global action agenda. Pritzker Brief 5. UCLA School of Law, Los Angeles, CA

* Gómez de Segura A, Tomas J, Pedraza SN, Crespo EA, Raga JA (2006) Abundance and distribution of the endangered loggerhead turtle in Spanish Mediterranean waters and the conservation implications. Anim Conserv 9:199-206

*Guerrini F, Mari L, Casagrandi R (2019) Modelling plastics exposure for the marine biota: risk maps for fin whales in the Pelagos Sanctuary (North-Western Mediterranean). Front Mar Sci 6:299

Hammer $\varnothing$, Harper DAT, Ryan PD (2001) PAST: palaeontological statistics, ver. 1.89. Palaeontol Electron 4:1-9

* Hatase H, Omuta K, Tsukamoto K (2007) Bottom or midwater: alternative foraging behaviours in adult female loggerhead sea turtles. J Zool (Lond) 273:46-55

*Hays GC, Hawkes LA (2018) Satellite tracking sea turtles: opportunities and challenges to address key questions. Front Mar Sci 5:432

*Hochscheid S, Bentivegna F, Bradai MN, Hays GC (2007a) Overwintering behaviour in sea turtles: dormancy is optional. Mar Ecol Prog Ser 340:287-298

* Hochscheid S, McMahon CR, Bradshaw CJA, Maffucci F, Bentivegna F, Hays GC (2007b) Allometric scaling of lung volume and its consequences for marine turtle diving performance. Comp Biochem Physiol A Mol Integr Physiol 148:360-367

*Hochscheid S, Bentivegna F, Hamza A, Hays GC (2010) When surfacers do not dive: multiple significance of extended surface times in marine turtles. J Exp Biol 213: 1328-1337

ISPRA (Istituto Superiore per la Protezione e la Ricerca Ambientale) (2015a) Technical Annex I. Fixed line transect using ferries as platform for observation monitoring cetacean macro fauna and main threats protocol. ISPRA, Rome

ISPRA (2015b) Technical Annex II. Marine litter and marine macro-fauna protocol for the agreement 'Fixed line transect using ferries as platform of observation for monitoring cetacean populations'. ISPRA, Rome

Jambeck JR, Geyer R, Wilcox C, Siegler TR and others (2015) Plastic waste inputs from land into the ocean. Science 347:768-771

Kauriano G, Panigada S, Casale P, Pierantonio N, Donovan GP (2011) Aerial survey abundance estimates of the loggerhead sea turtle Caretta caretta in the Pelagos Sanctuary, northwestern Mediterranean Sea. Mar Ecol Prog Ser 437:291-302

Lazar B, Borboroglu PG, Tvrtkovic N, Ziza V (2002) Temporal and spatial distribution of the loggerhead sea turtle, Caretta caretta, in the eastern Adriatic Sea: a seasonal migration pathway? In: Seminoff JA (ed) Tech Memo NMFS-SEFSC-503. NOAA, Miami, FL, p 283-284

Lazar B, Casale P, Tvrtkovic N, Kozul V, Tutman P, Glavic N (2004) The presence of the green sea turtle, Chelonia mydas, in the Adriatic Sea. Herpetol J 14:143-147

* Luschi P, Casale P (2014) Movement patterns of marine turtles in the Mediterranean Sea: a review. Ital J Zool 81: 478-495 
Luschi P, Mencacci R, Vallini C, Ligas A, Lambardi P, Benvenuti $S$ (2013) Long-term tracking of adult loggerhead turtles (Caretta caretta) in the Mediterranean Sea. J Herpetol 47:227-231

Luschi P, Mencacci R, Cerritelli G, Papetti L, Hochscheid S (2018) Large-scale movements in the oceanic environment identify high-use areas for loggerheads foraging in central Mediterranean Sea. Mar Biol 165:4

Maffucci F, Corrado R, Palatella L, Borra M and others (2016) Seasonal heterogeneity of ocean warming: a mortality sink for ectotherm colonizers. Sci Rep 6:23983

Mansui J, Molcard A, Ourmieres Y (2015) Modelling the transport and accumulation of floating marine debris in the Mediterranean basin. Mar Pollut Bull 91:249-257

Margaritoulis D, Argano R, Baran I, Bentivegna F and others (2003) Loggerhead turtles in the Mediterranean Sea: present knowledge and conservation perspectives. In: Bolten $\mathrm{AB}$, Witherington $\mathrm{BE}$ (eds) Loggerhead sea turtles. Smithsonian Books, Washington, DC, p 175-198

Matiddi M, Hochscheid S, Camedda A, Baini M and others (2017) Loggerhead sea turtles (Caretta caretta): a target species for monitoring litter ingested by marine organisms in the Mediterranean Sea. Environ Pollut 230: 199-209

Matsumura S, Nasu K (1997) Distribution of floating debris in the North Pacific Ocean: sighting surveys 1986-1991. In: Coe JM, Rogers DB (eds) Marine debris: sources, impacts, and solutions. Springer-Verlag, New York, NY, p 15-24

Narazaki T, Sato K, Abernathy KJ, Marshall GJ, Miyazaki N (2013) Loggerhead turtles (Caretta caretta) use vision to forage on gelatinous prey in mid-water. PLOS ONE 8: e66043

Nelms SE, Duncan EM, Broderick AC, Galloway TS, Godfrey MH, Hamann M, Godley BJ (2015) Plastic and marine turtles: a review and call for research. J Mar Sci 73:165-181

Putman NF, Mansfield KL (2015) Direct evidence of swimming demonstrates active dispersal in the sea turtle 'lost years'. Curr Biol 25:1221-1227

Pyle P, Carver M, Etherington L (2008) Methodology for debris monitoring during at sea observation programs in West Coast National Marine Sanctuaries. Final Report to NOAA Marine Debris Program. http://cordellbank.noaa. gov/science/debris_protocols_08.pdf

Rochman CM (2016) Strategies for reducing ocean plastic debris should be diverse and guided by science. Environ Res Lett 11:041001

Scales KL, Miller PI, Hawkes LA, Ingram SN, Sims DW, Votier SC (2014) On the front line: frontal zones as priority at-sea conservation areas for mobile marine vertebrates. J Appl Ecol 51:1575-1583

Schuyler QA, Wilcox C, Townsend K, Hardesty BD, Marshall NJ (2014) Mistaken identity? Visual similarities of marine debris to natural prey items of sea turtles. BMC Ecol 14:14

Editorial responsibility: Mark Hamann,

Townsville, Queensland, Australia
Shiomoto A, Kameda T (2005) Distribution of manufactured floating marine debris in near-shore areas around Japan. Mar Pollut Bull 50:1430-1432

* Snape RTE, Broderick AC, Çiçek BA, Fuller WJ, Glen F, Stokes K, Godley BJ (2016) Shelf life: neritic habitat use of a turtle population highly threatened by fisheries. Divers Distrib 22:797-807

Štrbenac A (2015) Strategy on the conservation of sea turtles in the Adriatic Sea for the period 2016-2025. Document produced under the NETCET project. IPA Adriatic Cross-border Cooperation Programme

* Suaria G, Aliani S (2014) Floating debris in the Mediterranean Sea. Mar Pollut Bull 86:494-504

Teuten EL, Saquing JM, Knappe DRU, Barlaz MA and others (2009) Transport and release of chemicals from plastics to the environment and to wildlife. Philos Trans R Soc B 364:2027e2045

* Thiel M, Hinojosa I, Vásquez N, Macaya E (2003) Floating marine debris in coastal waters of the SE-Pacific (Chile). Mar Pollut Bull 46:224-231

Thomas L, Buckland ST, Rexstad EA, Laake JL and others (2010) Distance software: design and analysis of distance sampling surveys for estimating population size. J Appl Ecol 47:5-14

Topcu EN, Tonay AM, Öztürk B (2010) A preliminary study on marine litter in the Aegean Sea. Rapp Comm Int Mer Médit 39:804

*Vannela R (2012) Are we 'digging our own grave' under the oceans? Biosphere level effects and global policy challenge from plastic(s) in oceans. Environ Sci Technol 46: 7932-7933

Vorisek P, Klvanova A, Wotton S, Gregory RD (eds) (2008) A best practice guide for wild bird monitoring schemes. RSPB, Sandy

*Wallace BP, DiMatteo AD, Bolten AB, Chaloupka MY and others (2011) Global conservation priorities for marine turtles. PLOS ONE 6:e24510

*Wilcox C, Mallos NJ, Leonard GH, Rodriguez A, Hardesty BD (2016) Using expert elicitation to estimate the impacts of plastic pollution on marine wildlife. Mar Policy 65:107-114

*Wildermann N, Critchell K, Fuentes MM, Limpus CJ, Wolanski E, Hamann M (2017) Does behaviour affect the dispersal of flatback post-hatchlings in the Great Barrier Reef? R Soc Open Sci 4:170164

Zampoukas N, Palialexis A, Duffek A, Graveland J and others (2014) Technical guidance on monitoring for the Marine Strategy Framework Directive. JRC Scientific and Policy Report. Scientific and Technical Research series, Report EUR 26499

Z Zbinden JA, Bearhop S, Bradshaw P, Gill B, Margaritoulis D, Newton J, Godley BJ (2011) Migratory dichotomy and associated phenotypic variation in marine turtles revealed by satellite tracking and stable isotope analysis. Mar Ecol Prog Ser 421:291-302

Submitted: March 25, 2019; Accepted: August 7, 2019 Proofs received from author(s): October 8, 2019 